\title{
Identity in the Digital Age: A Review of Information Technology Identity (ITID) Research in Information Systems
}

\author{
Hossein Mosafer \\ University of Tehran \\ mosafer@ut.ac.ir
}

\author{
Jalal Sarabadani \\ Washington State University \\ jalal.sarabadani@wsu.edu
}

\begin{abstract}
We live in a world of digital ubiquity, where use of information technologies (IT) has permeated every single aspect of our daily life. Carter and Grover (2015) introduced IT identity (ITID) as a measurable construct into IS literature to explain this intertwinement. Since then, it has provided a theoretical foundation for behavioral research in various contexts in IS and other disciplines as well. To reach a better understanding of this emerging phenomenon of interest and the current state of knowledge, this paper aims to review and analyze the increasing literature on ITID concerning its antecedents and consequences in its nomological network. As the first literature review on ITID construct in IS research, this paper contributes to the overall understanding of ITID in order to demonstrate the importance of ITID in a wide range of behavioral IS topics.
\end{abstract}

\section{Introduction}

Who am I? Whether it is put in words or crossed as thoughts, the answer to this question in relation to some social category or object defines one's identity [1], [2]. Identities can be developed at the collective or individual level, and also in relation to material objects (including IT). In everyday life, we are increasingly dependent on using IT-related tools for maintaining relationships with family and friends, delivering workrelated tasks, and even playing games for entertainment [3].

The use of IT has permeated every aspect of our lives, and "has become increasingly intertwined with [our] personal and social routines" [4]. Also, "with the proliferation of technology into every aspect of daily life, the sense of self has become increasingly linked to interacting with the technology" [5]. So as to represent this intertwinement, Carter and Grover conceptualized ITID as "the extent to which a person views use of an IT as integral to his or her sense of self" [4].
According to Carter and Grover [4], people may consider IT as an integral part of the self that leads their behavioral choices, and those who strongly self-identify with IT (compared to those who do not) are expected to engage more in IT use behaviors. They maintain that ITID can enrich our understanding and prediction of individuals' thoughts and behaviors within different social contexts.

Research on the link between identity and behavior also provides strong evidence on the influence of identity on behavior [6]-[8]. More importantly, prior research shows that in recurring behaviors, identity is the key predictor of behavioral outcomes [8]. Thus, it is important to explore the factors affecting ITID, which in turn influences behavioral outcomes. It is also important to investigate the consequences of ITID as it helps us to better understand individuals' behavior under the presence of ITID.

Now, five years after the introduction of ITID construct by Carter and Grover [4] into IS literature, the analysis of recent studies shows that ITID is providing a theoretical foundation for behavioral research in various IT contexts. The present study aims to review the emerging research on this subject matter in information systems literature. As Webster and Watson suggest, "tackling an emerging issue that would benefit from exposure to potential theoretical foundations" can create a solid foundation for evolving knowledge [9]. Reviews of emerging constructs, such as ITID will also help researchers to better incorporate this construct in their own work.

Our main research question is, how ITID is used in IS literature? In order to tackle the research question more accurately, we formulate it more specifically as follows:

- What are the antecedents to ITID in IS literature?

- What are the consequences of ITID in IS literature?

The paper advances as follows. We begin by elaborating on ITID theoretical background. Next, to evaluate the current understanding of the research area in IS domain, we present a descriptive analysis on the 
topic. Then, we provide an analysis of ITID in IS research regarding its antecedents and consequences. Finally, we conclude the paper by discussing what we know so far about ITID research, what we do not know, and where we need to head from here.

\section{Theoretical Foundation}

Considering the nature and influence of identity as created by society, identity theories fall into two broad categories of collective and individual level [10]. Identity theories at collective level, like social identity [11], are focused on how identity is formed through membership in social groups or any other social categories. While at the individual level, the focus is on explaining the way networks of roles and relationships, in which people are surrounded, are affecting their identity and in turn their behavior [10], [12].

Identity theories assume that individuals actively rely on their identities to define and change situations. [13]. In other words, they look for self-continuity and self-esteem through creating a congruency between the meanings they hold as identities and the perceptions of who they are as perceived by others, or even themselves [12].

The relationship between IT and identity has recently been an issue of importance among IS researchers [4], [14]-[16]. Carter and Grover [4] reviewed 50 articles, published in major IS journals during the period 1997-2014 and found that existing literature considers IT and identity as separate entities. They proposed a different approach, in which the emphasis is on the mutually formed relationship between technology and its social context.

By defining IT as "a unit of technology (hardware device, software application, or software application environment) with which an individual consciously engage", they define ITID as "the extent to which an individual views use of an IT as integral to his or her sense of self' - a higher-order construct representing three dimensions of relatedness, emotional energy, and dependence; i.e., the extent to which an individual expresses feelings of connectedness (relatedness), confidence, enthusiasm, and energy (emotional energy), and reliance (dependence) when thinking about her/himself in relation to an IT.

Carter et al. [17] further expanded ITID theory by proposing the existence of four different identity clusters: (1) ITID, in which people consider using technology calming, appealing, essential, and feel connected when it is available to them; (2) Disidentification, in which the use of the [target IT] is completely unrelated to the sense of self; (3) Anti-ITID, where individuals find technology frustrating, controlling, and manipulative; and (4) Ambivalent
ITID, where positive and negative self-identification coexist.

Carter and Grover [4] believe that considering ITID is crucial for various IS topics in relation to human behavior. ITID has already provided a theoretical foundation for behavioral research in various IT contexts, including online consumer behavior [18], [19], dark side of IT use [20], [21], healthcare [22]-[24], organization [25]-[28], social media [29]-[33], personal IT [34]-[36], green IT [37], information security [38], information system development [39], and more.

\section{Methodology}

The review methodology in this paper is rather different from ordinary literature review papers, which are usually guided by Webster and Watson [9] (e.g., [40], [41]). The literature on the relationship between IT and identity as distinct entities has been previously reviewed and analyzed by a number of researchers [14][16]. Carter and Grover [4] conducted a review in 2015, which covered major prior review studies on the topic, and focused on the mutually constitutive relationship between technology and its social context - i.e., they introduced a single ITID construct instead of IT and identity as separate constructs. Accordingly, and based on the arguments mentioned above, we used Carter and Grover's conceptualization [4] as our baseline and looked at all papers that cited this paper into their studies as it is the first work to introduce ITID in the literature. The scope of the present review is thus limited to those studies which included ITID and its contextualized variations as a construct in their research model.

Of the initial 139 papers that cited Carter and Grover [4], we excluded 9 non-English studies and one special issue call for participation. The full text of the remaining papers was read and consequently another 106 papers were excluded based on the previouslydetermined exclusion criteria, as follows: (1) papers that mentioned ITID, but did not include ITID construct as part of their research model (101 papers excluded) (2) papers that used ITID construct, but were descriptive in nature and merely provided a framework instead of a research model (5 papers excluded). Research-inprogress papers and dissertations were not excluded as we wanted to review this emerging research topic. This screening process resulted in 24 papers, including 9 journal articles, 12 conference papers, and 3 dissertations. 


\section{Findings}

\subsection{Descriptive Analysis of ITID Research}

The descriptive analysis of selected papers reveals a steady increase in the publication of ITID-related papers, with 2019 accounting for almost 50\% of published research papers in the past 5 years. The trend is an indication of the attractiveness of the topic among researchers as an emerging topic.

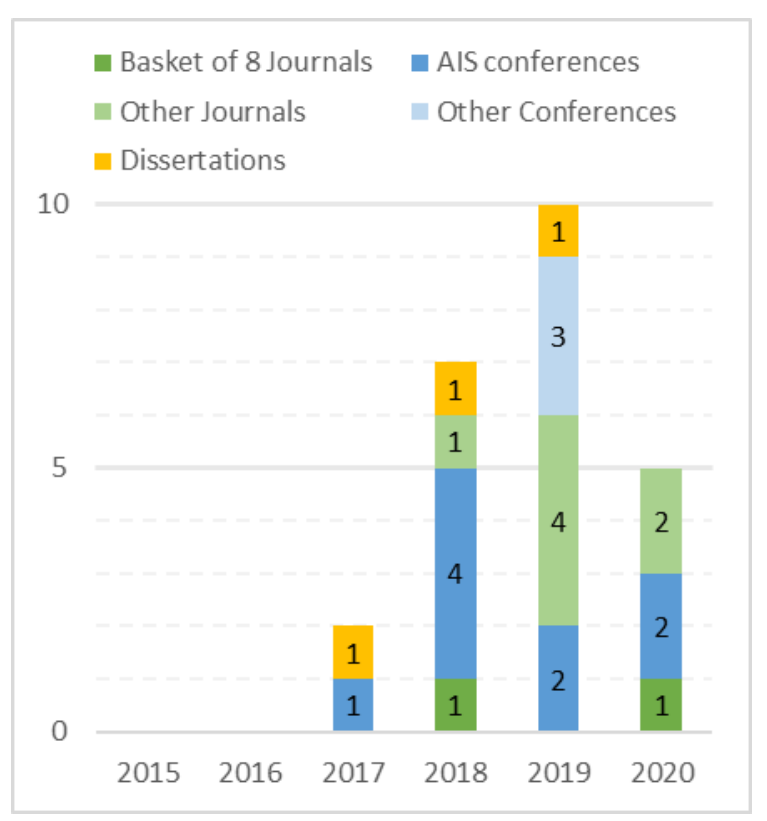

Figure1. ITID studies by year and publication

We also classified ITID research by publication. Figure 1 shows the different outlets in which ITID research has been published. Our classification was based on two major criteria: (1) papers published in IS senior journals (also known as basket of eight ${ }^{1}$ ) and AIS conferences (AMCIS, ICIS, HICSS, ECIS and PACIS) and (2) papers published in other journals and conferences were classified as others ${ }^{2}$. Results show that AIS conferences are the most attractive outlets among others. This can be explained by several reasons. First, ITID construct was born in the IS literature and AIS conferences are the main outlets for IS researchers. Moreover, conferences are the most suitable destinations to publish newborn ideas and a great place to receive feedback on initial version of papers. The number of papers being published in journals out of the basket is also on the rise consisting of diverse outlets,

\footnotetext{
${ }^{1}$ MISQ, ISR, JMIS, JAIS, ISJ, EJIS, JIT and JSIS

2 The classification was done for the sake of simplicity and save of space. Details of publication outlets are available upon request.
}

which indicate the attractiveness of the idea in different disciplines (e.g., communication science [42]). Also, the low number of ITID research in the basket of eight can be explained by the fact that the review cycle in such outlets takes a significant amount of time, in addition to the low acceptance rate of research papers in such outlets. However, based on our analysis we should expect to see more research papers in this area soon.

\subsection{Antecedents to ITID}

So far, a number of theories are used to explain the formation of ITID within different contexts, such as self-efficacy ${ }^{3}$ [24], [42], valence framework [35], theory of planned behavior [37], protection motivation theory [31], [38], person-environment fit [43], social identity, and role identity [28] to mention a few.

Our review of the literature reveals a wide range of antecedents to ITID being studied in IS literature. These factors, as shown in table 1, can be categorized into four major groups based on the nature of their research: individual, technology, organizational, and social factors.

4.2.1. Individual Factors. The individual factors are the most frequently studied antecedents of ITID. A number of these studies validate the original ITID conceptual model, while others introduce new individual factors as predictors of ITID construct.

Consistent with the ITID conceptual model, Gong et al. [20] and Esmaeilzadeh [36] find that self-efficacy, perceived enjoyment, and embeddedness are positively related to ITID. The findings of Eidhof [42] also confirm that individuals with higher perceptions of selfefficacy and actualized rewards have higher levels of ITID. Balapour et al. [24] conclude that patients with more related IT experience, are more likely to identify themselves with mobile technology. There are also two research-in-progress papers seeking to understand the role of experiences in mediating the relationship between technology affordances and ITID [27], and validate the original conceptual model on ITID in a fitness IT context [34]. Overall, the studies above replicate ITID predictors in different studies and the results are consistent among them.

There are also studies in this category going beyond the original conceptual model to introduce antecedents of ITID. For instance, in the context of social media, Polites et al. [21] confirm that the more an individual uses Facebook to socialize with others, and uses it for a wide range of tasks, the higher the possibility that the

\footnotetext{
${ }^{3}$ Citations refer to ITID related studies in which these theories were used.
} 
Table 1. Prior research on the antecedents to ITID

\begin{tabular}{|c|c|c|c|c|}
\hline & Antecedents & ITID Constructs & Major Contexts & Citations \\
\hline 㺼 & $\begin{array}{l}\text { Usage; Habit; Self referencing; } \\
\text { Related IT Experience; } \\
\text { Environmental Passion; } \\
\text { Impression Development; } \\
\text { Impression Verification; Self- } \\
\text { efficacy; Actualized rewards; } \\
\text { User Satisfaction; Belongingness; } \\
\text { Perceived Privacy Concern; } \\
\text { Embeddedness; Perceived } \\
\text { Enjoyment; Emotional Value }\end{array}$ & $\begin{array}{l}\text { IT Identity; Social } \\
\text { Networking Sites (SNS) } \\
\text { Identity; Mobile } \\
\text { Technology Identity } \\
\text { (MTI); Green IT } \\
\text { Identity; Fitness IT } \\
\text { Identity (FITI); } \\
\text { Smartwatch Identity; } \\
\text { Identity Salience }\end{array}$ & $\begin{array}{l}\text { Dark side of IT use; } \\
\text { Healthcare; Green IT; } \\
\text { Enterprise Social Media } \\
\text { (ESM); Social Media; } \\
\text { Elementary School Teachers; } \\
\text { personal IT (Smartwatch); } \\
\text { Online consumer behavior }\end{array}$ & $\begin{array}{l}{[18],[19],} \\
{[42],[20],} \\
{[21],[27],} \\
{[30],[34]-} \\
{[37]}\end{array}$ \\
\hline 宊 & $\begin{array}{l}\text { Technology-value Fit; } \\
\text { Technology affordances; } \\
\text { Functionality (Usability); IT } \\
\text { Dynamism }\end{array}$ & IT Identity & $\begin{array}{l}\text { General; Enterprise Social } \\
\text { Media (ESM); } \\
\text { Elementary School Teachers }\end{array}$ & $\begin{array}{l}{[27],[42],} \\
{[43]}\end{array}$ \\
\hline 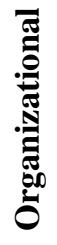 & $\begin{array}{l}\text { Cybersecurity Training; Support; } \\
\text { Obligation; } \\
\text { Moderation/Mitigation Strategies; } \\
\text { Job Role Identity; Organizational } \\
\text { Identity }\end{array}$ & $\begin{array}{l}\text { IT Identity; IT Identity } \\
\text { with Artificial } \\
\text { Intelligence (AI) }\end{array}$ & $\begin{array}{l}\text { InfoSec; Elementary School } \\
\text { Teachers; Social Networking } \\
\text { Sites (SNS); Artificial } \\
\text { Intelligence in Organization }\end{array}$ & $\begin{array}{l}\text { [28], [31], } \\
{[38],[42]}\end{array}$ \\
\hline 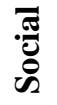 & Social Interactions; Social Value & $\begin{array}{l}\text { Smartwatch Identity; } \\
\text { Identity Salience }\end{array}$ & $\begin{array}{l}\text { personal IT (Smartwatch); } \\
\text { Online consumer }\end{array}$ & {$[18],[35]$} \\
\hline
\end{tabular}

individual will feel emotionally energized by and linked to Facebook, and the more dependent upon it he/she will become. Furthermore, Facebook users assume at least part of their social network sites (SNS) identity based on their social media usage habits. Also, an experiment research by Huang [44] reveals that online consumers can closely relate their sense of self to tangible and vivid simulations of product usage through augmented reality (i.e., self-referencing fosters their ITID). Moreover, environmental passion is found to be an important indicator of favorable green IT attitude, directly related to green ITID [37].

Also, another research idea [30] aims to study ITID formation in the context of social media by proposing that the use of social media continually modifies ITID through impression development and impression verification. Additionally, benefits of social interactions and belongingness are found to be more important to individuals than privacy risks in building their IT/smartwatch identity [35]. Finally, Oyedele and Simpson [18] show that users who see more emotional value in using entertainment streaming apps, are more likely to consider it as a central part of who they are. As the results suggest, ITID can be easily adopted in other contexts as well and help in the accumulation of knowledge in the field.

4.2.2 Technology Characteristics. While the original conceptual ITID model posits that experiences mediate the relationship between technology characteristics and ITID, there are studies that measured the direct influence of technology characteristics on ITID with significant results.

In their qualitative study, Weng et al. [43] find that IT characteristics, when aligned with people's personal values, create a fit that fosters the development of ITID. Additionally, Eidhof [42] concludes that when teachers feel technologies are easy to use, not complex, and wellintegrated, they have a higher ITID perception. Also, IT dynamism does not have a significant relationship with ITID, indicating that in self-identifying with IT, it does not matter whether the IT is changing too much for elementary school teachers. There is also a research-inprogress attempting to understand the impact of technology affordances on identifying the self with technology (ITID), as well as the mediating role of experiences in this relationship [27], proposing that those who highly perceive enterprise social media affordances consistently look for opportunities to 
assimilate these affordances into their self-concept which in turn strengthen IT identity.

4.2.3. Organizational Factors. The way employees identify themselves with their organization along with trainings and support they receive is shown to be influencing their ITID. Alahmad and Robert [28] conclude that identifying with organizations (how much an individual's membership in his or her organization is self-defining) and the work roles (how much someone depends on his or her work role to define who he or she is) leads to more strongly identifying with the technology (artificial intelligence (AI) systems in this study) used in the workplace. Another example is a research by Eidhof [42], which finds that the more teachers feel their school supports them when using technologies in the classroom, the more they will identify themselves with an IT artifact. Also, it is hypothesized that the more teachers feel obligated to use IT, the less they will incorporate an ITID. However, the results are not supported.

There are also organizational factors proposed to be antecedents of ITID which have remained mere propositions and need to be tested. For example, Shi et al. [38] prompt a research idea trying to understand whether immersive cybersecurity training affects ITID. Another in-progress study aims to provide an initial understanding of how to combat SNS addiction from an IT/SNS identity perspective. The premise of the research is that training to combat or prevent SNSs addiction increases SNS identity levels [31].

4.2.4. Social Interactions. Our review of the literature reveals a number of studies dealing with social factors as significant predictors of ITID. For example, Ogbanufe and Gerhart [35] find that smartwatchenabled social interactions are important in strengthening smartwatch identity of individuals. Oyedele and Simpson [18] also confirm that when users see more social value in using entertainment streaming apps, they are more likely to consider it as an important part of who they are.

\subsection{Consequences of ITID}

The consequences of ITID have also been a topic of interest among IS researchers. As shown in table 2, varied theories have been incorporated to study the consequences of ITID, including but not limited to theory of planned behavior ${ }^{4}$ [37], cognitive appraisal theory [22], flow theory [29], IS infusion behavior [25], media dependency theory, and uses and gratifications

\footnotetext{
${ }^{4}$ Citations refer to ITID related studies in which these theories were used.
}

theory [32]. Our review of the literature shows that consequences of ITID can be categorized into cognitive, affective, behavioral intention, actual behavior, and individual performance. These studies are reported in more detail in sequence.

4.3.1. Cognitive Consequences. The influence of ITID on cognition has been studied in several contexts. For example, research shows that employees' identification with enterprise social media (ESM Identity) promotes co-worker support, which in turn increases job satisfaction and performance [26]. Interestingly, Gong et al. [20] show that ITID positively influences maladaptive cognitions (intrusive thought and thought suppression) through distorting perceptions, which in turn collectively predict problematic online gaming and fully mediate the effect of ITID on problematic online gaming. Furthermore, a study by Hassandoust [25] confirms that employees' identity in relation to a specific IS becomes related to who they are in the roles they perform within an organization (i.e., Employees who are personally attached and dependent on a system to do their job tasks are likely to perform roles that are in line with their identity). Lastly, the results of Nash and Wakefield [37] also indicate that green ITID has a direct influence on green IT attitude.

There are also cognitive consequences proposed by researchers which have remained mere propositions and need to be further tested. As an example, it is posited that if patients strongly identify themselves with IT, they will put more value to the feedback from IT. Savoli and Bhatt [22] direct future research to test this proposition. Another study also proposes that in conjunction with traditional flow experiences, group members' ITID and social identification with the group will be key predictors of group flow experiences [29].

4.3.2. Affective Consequences. Affective consequences of ITID have also been investigated in a number of studies. For example, Huang [44] show that if customers form a connection and emotional attachment with the try-on technology (and self-identify with it), then it successfully stimulates their brand love. The results of Gong et al. [20] also confirms that ITID positively influences negative emotion anticipation, which in turn predicts problematic online gaming and fully mediate the effect of ITID on problematic online gaming. However, the effect of emotion irreplaceability is not statistically significant. In addition, Savoli and Bhatt [22] propose that if patients strongly identify themselves with IT, they will have stronger positive emotions about IT but remained untested. Overall, our 
Table 2. Prior research on the consequences of ITID

\begin{tabular}{|c|c|c|c|c|}
\hline & Consequences & ITIDs & Major Contexts & Citations \\
\hline 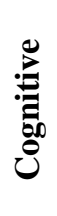 & $\begin{array}{l}\text { Evaluation of IT feedback; Co-worker } \\
\text { support; Group Flow; Attitude; } \\
\text { Intrusive Thought; Thought } \\
\text { Suppression; IS Infusion Role Identity }\end{array}$ & $\begin{array}{l}\text { IT Identity; } \\
\text { Enterprise Social } \\
\text { Media (ESM) } \\
\text { identity; Green IT } \\
\text { Identity }\end{array}$ & $\begin{array}{l}\text { Healthcare; Organization } \\
\text { (Enterprise Social Media); } \\
\text { Social Media; Green IT; } \\
\text { Problematic online gaming; } \\
\text { Organization (CRM) }\end{array}$ & $\begin{array}{l}{[20],[22],} \\
{[25],[26],} \\
{[29],[37]}\end{array}$ \\
\hline : & $\begin{array}{l}\text { Brand love; Emotions about IT; } \\
\text { Emotion Irreplaceability; Negative } \\
\text { Emotion Anticipation }\end{array}$ & IT Identity & $\begin{array}{l}\text { AR in clothes-fitting and } \\
\text { shopping; Healthcare; } \\
\text { Problematic online gaming }\end{array}$ & $\begin{array}{l}{[19],[20],} \\
{[22]}\end{array}$ \\
\hline : & $\begin{array}{l}\text { Intention to Use; Security Behavioral } \\
\text { Intention; Intention to Practice Green } \\
\text { IT }\end{array}$ & $\begin{array}{l}\text { IT Identity; Mobile } \\
\text { Technology Identity } \\
\text { (MTI); Green IT } \\
\text { Identity }\end{array}$ & $\begin{array}{l}\text { Mobile Healthcare Apps; } \\
\text { Information Security; Green } \\
\text { IT }\end{array}$ & $\begin{array}{l}{[24],[37],} \\
{[38]}\end{array}$ \\
\hline : & $\begin{array}{l}\text { Deficient Self-Regulation of Time; } \\
\text { Extended Use Integrative Use; } \\
\text { Emergent Use; Decision-making } \\
\text { behavior; SNS Addiction; Word of } \\
\text { mouth; Information Seeking; } \\
\text { Information Sharing; Communication; } \\
\text { Solitary Play; Media Preference; } \\
\text { Elect. Media Use; Deep Use of } \\
\text { Smartwatch; Feature Use Behavior; } \\
\text { Enhanced Use Behavior; Hours of } \\
\text { use; Recommending to use; Self- } \\
\text { report Reliability }\end{array}$ & $\begin{array}{l}\text { IT Identity; SNS } \\
\text { Identity; Fitness IT } \\
\text { Identity (FITI); } \\
\text { Social Media } \\
\text { Dependence; } \\
\text { Electronic Media } \\
\text { Identity; Smartwatch } \\
\text { Identity; Identity } \\
\text { Salience; Mobile } \\
\text { Technology Identity } \\
\text { (MTI) }\end{array}$ & $\begin{array}{l}\text { Dark side of IT use; } \\
\text { Organization (CRM); } \\
\text { IT Project (teams); Social } \\
\text { Networking Sites (SNS); } \\
\text { computer-mediated } \\
\text { communication; personal IT } \\
\text { (Smartwatch); Online } \\
\text { consumer behavior; } \\
\text { Healthcare }\end{array}$ & $\begin{array}{l}{[21],[23],} \\
{[25],[31]-} \\
{[36],[39],} \\
{[45],[46]}\end{array}$ \\
\hline 巳 & $\begin{array}{l}\text { innovative individual performance; } \\
\text { Job Performance }\end{array}$ & $\begin{array}{l}\text { Smartwatch Identity; } \\
\text { IT Identity with AI }\end{array}$ & $\begin{array}{l}\text { personal IT (Smartwatch); } \\
\text { Artificial Intelligence }\end{array}$ & [28], [35] \\
\hline
\end{tabular}

conclusion from the limited research in the interaction between ITID and emotions elicited among individuals highlighted that ITID does not always lead to positive emotions and negative emotions might be expected, especially in cases where IT use becomes problematic such as IT addiction.

4.3.3. Behavioral Intentions. Behavioral intention has a key role in determining behavior [47]. With this regard, three studies have investigated intentions as consequences of ITID. For example, a study by Balapour et al. [24] indicate that perceived mobile technology identity (MTI) positively influences patients' perceived intentions to adopt mHealth apps provided by clinics or hospitals. Green IT identity is also found to have a direct influence on green IT intentions, suggesting a contribution to behavior that is independent of attitude. Theoretically, the findings imply that green
ITID plays a substantive role in behavioral intentions beyond that of attitude and perceived behavioral control in a TPB framework [37]. Finally, Shi et al. [38] prompt a research idea in pursuit of answering whether ITID affects security behavioral intention. The consistent findings in prior literature suggest that ITID is a key determinant of IT use intentions.

4.3.4. Actual Behavior. Our review of the literature shows that research in the area has not solely measured the influence of ITID on intention behavior, but also its influence on actual behavior as well, which is in line with the original ITID conceptual model. For instance, a study by Hassandoust [25] shows that employees openly embrace IS infusion behavior (extended, integrative, and emergent use) when they have strong reliance, emotional attachment and dependency on the IS. Furthermore, stronger self-identification with smartwatch increases deep use of it. It also mediates the 
effects of social interactions, belongingness, and privacy concerns on deep use [35].

Two more studies aim to validate the original ITID conceptual model in the context of personal health devices: the study by Esmaeilzadeh [36] reveals that if individuals self-identify with a personal health device (PHD), they are more likely to search for previously unused feature sets of the PHDs (enhanced use), apply smart devices in additional situations, and use components of extension capabilities (extended features). Sundrup et al. [34] also hypothesize that the more a customer self-identifies with a fitness IT, the more she/he is likely to recommend it to others.

The behavior of social media users has also been among the interests of IS researchers regarding ITID. For example, when Gen Y users are more dependent on social media (as part of their ITID), they seek higher gratifications from using mobile social media to fulfill their needs regarding emergency responding ( $\mathrm{Li}$ et al 2019). The stronger an individual identifies her/himself with an electronic communication media (ECM), the more likely are the chances of manifesting a preference for this media to solve the proposed managerial task and the more frequently he/she will use the electronic communication media set [33]. Also, the likelihood of recommending entertainment streaming apps (ESA) and the hours of using ESA increases when users see selfservice streaming apps as an important part of who they are [18].

Interestingly, there are two studies examining the role of ITID in dark side of IT use behaviors. An inprogress study by Boroon et al. [31] aims to provide an initial understanding of what predicts SNS addiction and how to combat it from an IT/SNS identity perspective. Authors maintain that ITID is likely to moderate or mitigate SNS addiction through training. Moreover, Polites et al. [21] conclude that Individuals who strongly self-identify with Facebook realize that their interconnectedness with SNS is causing them problems with organizing their time.

Finally, Schmalz et al. [39] merely propose a research idea and are in pursuit of understanding whether self-identification with an IT under development affects project team members' personal risk-related decision-making behavior on IT projects.

4.3.5. Individual Performance. Not only does ITID influence IT use behaviors, it also affects the individual performance of IT users. For instance, stronger selfidentification with smartwatch increases innovative individual performance. It also mediates the effects of social interactions, belongingness, and privacy concerns on innovative individual performance [35]. Additionally, identifying with a technology at the workplace (e.g., AI systems) shows to increase job performance of employees [28]. However, ITID has not always been influential in determining the performance of individuals. For example, Reychav et al. [23] propose that patients with more mobile technology identity are more accurate in reporting their health status, which was not supported.

\section{Discussion}

\subsection{What is the current state of ITID research?}

Our review of ITID research in IS provides the following key findings. First, a growing embeddedness of IT in our daily lives has made ITID a topic of increasing importance for the behavioral side of IS. As the descriptive analysis of prior literature suggests, ITID is expected to receive more attention among IS researchers, especially in conducting empirical studies.

Second, most research considering ITID has been quantitative in nature, except for the two studies in which a mixed-method approach was incorporated [34], [43]. Furthermore, two research-in-progress studies have also recommended using mixed-method [39] and qualitative [31] approaches in order to study projectrelated behavior and SNS addiction respectively.

Third, the analysis of 5 years of research on ITID shows that ITID is a key determinant of various cognitive and affective consequences, behavioral intentions, IT use and IS-related behaviors, as well as individual performance - highlighting the importance of considering ITID construct in various contexts while conducting empirical studies on the behavioral aspect of information systems.

Finally, ITID has mostly been studied as a mediator in predicting the behavioral outcomes. Also, in studying ITID formation, it has been treated as a dependent variable. Therefore, a considerable amount of research has investigated the antecedents to ITID, the results of which confirm the significant influence of diverse individual, technological, organizational, and social factors on this phenomenon of interest.

\subsection{What can be done in the future?}

Consideration of demographics is of importance in behavioral IS research. Demographic and individual characteristics can impact the perception and reaction of individuals in IT use behaviors [48], [49]. Future research could study the influence of variables like age, gender, education, personality traits on individuals' selfidentification with IT in emerging contexts, such as personal IT devices. 
"Because individuals interact with many IT, they can develop many IT identities" [4]. Development of multiple ITIDs in individuals toward different IT artifacts at the same time has been entirely neglected in the current ITID literature. One might strongly selfidentify with an IT (e.g., productivity apps and personal health devices), while exposing no or even negative identification with other ITs (e.g., social media). The interaction of multiple ITIDs, along with the possible incongruencies between them, and their overall impact on intention, behavior, cognition, and performance still remains a fruitful research path for future studies.

Similarly, little attention is given to the feedback effect of behavior on ITID, which can result in maintaining the self (as in the identity verification process) or ITID change over time. It would be no surprise if self-identification with an IT is diminished or even strengthened as individuals obtain new experiences regarding that IT. Tackling this research area would be possible through conducting longitudinal studies, as it is important in determining IT use and adoption behaviors.

Almost all studies examined ITID at the individual level. However, a recent study by You and Robert [50] shows that robotic teams perform better and are more viable when they were emotionally attached to their robots. Curley and Polites [29] also hypothesized that group members' ITID and social identification with the group will be key predictors of group flow experiences, which was left to be further tested empirically. Such examples highlight the key role of collective ITID where team performance is given more attention than individual performance (e.g., agile software development and project teams, to mention a few). Therefore, new theoretical work is needed to expand current understanding of ITID at collective level.

Resistance behaviors like apathy, passive resistance, and active resistance [51] have not been studied in any prior ITID research, though included in the original ITID conceptual model - making it a fruitful research opportunity for future studies.

Our review of consequences revealed an interesting question about ITID, that is whether we should always expect favorable outcomes when ITID is high in individuals. More investigation on how and under what conditions ITID is associated with negative outcomes is of interest and can enhance our understanding of the ITID construct. More specifically, using qualitative methods would enable researchers to understand the mechanism through which higher levels of ITID in individuals leads to negative outcomes as the literature on the negative consequences of ITID is scant [52].

Furthermore, dark side of IT use behaviors have also not received proportionate attention in prior studies. So far, three studies have investigated the influence of
ITID on deficient self-regulation of time [21], SNS addiction [31], and problematic online gaming [20]. Applying ITID within dark side of IT use context provides a better understanding of such behaviors like technostress, information overload, IT addiction, and IT anxiety. In the context of technostress, for example, research is showing that not all technostress creators are negative [53], [54]. From appraisal perspective in psychological stress, ITID can be used in technostress research to explain why some individuals perceive technostress as a positive phenomenon (eustress) and why some perceive it as a negative phenomenon (distress).

Lastly, research in IS literature has shown that cognitive models are not capable of fully explaining individuals' behavior [55]. For instance, in the context of new IT implementation, Beaudry and Pinsonneault [56] and Stein et al. [57] found that individuals show mixed emotional responses to new IT in organizations. In a similar vein, future research can integrate ITID in affective based models to investigate whether ITID is only associated with positive emotions, negative emotions, or even both. This will allow researchers to better understand outcomes such as individuals' IT use patterns.

\subsection{Limitations}

As we aimed to review the literature on the intertwinement of IT and identity as a single construct (not separate entities), the scope of the present study is thus limited to ITID conceptualization by Carter and Grover [4]. In other words, only the studies were included that used ITID construct in their research model. Apparently, we make no claims to have conducted an inclusive review.

\section{Conclusion}

The present study, as the first literature review on ITID, contributes to better understanding of the current IT identity (ITID) research in IS by analyzing the antecedent and consequences of ITID construct in its nomological net. We analyzed 24 studies since 2015 (the time ITID was introduced to IS literature by Carter and Grover), which included ITID as a construct in their research model. A considerable number of factors categorized within four groups of individual, technological, organizational, and social were found to influence ITID as its antecedents. ITID was also found to result in cognitive and affective consequences, behavioral intentions, actual behavior, and individual performance. The results reveal that ITID has already provided a theoretical foundation for behavioral research in a wide range of contexts from consumer 
behavior and organization to social media and personal IT devices. This study also paves the path for the future direction of ITID research to enrich its knowledge domain by proposing some research directions.

\section{References}

[1] G. J. McCall, 'The Me and the Not-Me', in Advances in Identity Theory and Research, Boston, MA: Springer US, 2003, pp. 11-25.

[2] V. L. Vignoles, S. J. Schwartz, and K. Luyckx, 'Introduction: Toward an Integrative View of Identity', in Handbook of Identity Theory and Research, New York, NY: Springer New York, 2011, pp. 1-27.

[3] S. J. Mcmillan and M. Morrison, 'Coming of age with the internet', New Media Soc., vol. 8, no. 1, pp. 73-95, 2006.

[4] M. Carter and V. Grover, 'Me. My Self, and I(T): Conceptualizating Information Technology Identity and its Implications', Manag. Inf. Syst. Q., vol. 39, no. 4, Dec. 2015.

[5] M. Carter, V. Grover, and J. B. Thatcher, 'Mobile Devices and the Self', in IGI Global, IGI Global, 2013, pp. 150-164.

[6] H.-W. Charng, J. A. Piliavin, and P. L. Callero, 'Role Identity and Reasoned Action in the Prediction of Repeated Behavior', Soc. Psychol. Q., vol. 51, no. 4, p. 303, Dec. 1988.

[7] D. Granberg and S. Holmberg, 'The IntentionBehavior Relationship Among U.S. and Swedish Voters', Soc. Psychol. Q., vol. 53, no. 1, p. 44, Mar. 1990.

[8] J. E. Stets and C. F. Biga, 'Bringing Identity Theory into Environmental Sociology', Sociol. Theory, vol. 21, no. 4, pp. 398-423, Dec. 2003.

[9] J. Webster and R. T. Watson, 'Analyzing the Past to Prepare for the Future: Writing a Literature Review', $M I S Q$., vol. 26, no. 2, pp. xiii-xxiii, Jun. 2002.

[10] S. Stryker and P. J. Burke, 'The Past, Present, and Future of an Identity Theory', Soc. Psychol. Q., vol. 63, no. 4, p. 284, Dec. 2000.

[11] H. Tajfel, Human groups and social categories: studies in social psychology. Cambridge University Press, 1981.

[12] P. J. Burke and J. E. Stets, Identity theory. 2009.

[13] P. J. Burke and D. C. Reitzes, 'An Identity Theory Approach to Commitment', Soc. Psychol. Q., vol. 54, no. 3, p. 239, Sep. 1991.

[14] U. Gal and A. L. Kjærgaard, 'Identity in organizations: A review of information systems research', in The 17th European Conference on Information Systems (ECIS) 2009, 2009.

[15] H. Nach and A. Lejeune, 'The impact of information technology on identity: Framing the research agenda', in Proceedings of the Administrative Sciences Association of Canada (ASAC) Conference, 2009.

[16] E. A. Whitley, U. Gal, and A. Kjaergaard, 'Who do you think you are? A review of the complex interplay between information systems, identification and identity'. Taylor \& Francis, 2014.

[17] M. Carter, D. Compeau, and M. Schmalz, 'The Ambivalent Potential of IT Identity: Me, Not-Me, and Conflicted Me in a Digital World', in Proceedings of the Twenty-third DIGIT pre-ICIS Workshop, 2018.

[18] A. Oyedele and P. M. Simpson, 'Streaming apps: What consumers value', J. Retail. Consum. Serv., vol. 41, pp. 296-304, Mar. 2018.

[19] T.-L. Huang, 'Psychological mechanisms of brand love and information technology identity in virtual retail environments', J. Retail. Consum. Serv., vol. 47, pp. 251-264, Mar. 2019.

[20] X. Gong, C. Chen, and M. K. O. Lee, 'What drives problematic online gaming? The role of IT identity, maladaptive cognitions, and maladaptive emotions', Comput. Human Behav., p. 106386, Apr. 2020.

[21] G. L. Polites, C. Serrano, J. B. Thatcher, and K. Matthews, 'Understanding social networking site (SNS) identity from a dual systems perspective: an investigation of the dark side of SNS use', Eur. J. Inf. Syst., vol. 27, no. 5, pp. 600-621, 2018.

[22] A. Savoli and M. Bhatt, 'The impact of IT identity on users' emotions: A conceptual framework in health-care setting', AMCIS 2017 - Am. Conf. Inf. Syst. A Tradit. Innov., vol. 2017-Augus, 2017.

[23] I. Reychav, R. Beeri, A. Balapour, D. R. Raban, R. Sabherwal, and J. Azuri, 'How reliable are selfassessments using mobile technology in healthcare? The effects of technology identity and self-efficacy', Comput. Human Behav., vol. 91, pp. 52-61, Feb. 2019.

[24] A. Balapour, I. Reychav, R. Sabherwal, and J. Azuri, 'Mobile technology identity and selfefficacy: Implications for the adoption of clinically supported mobile health apps', Int. J. Inf. Manage., vol. 49, no. October 2018, pp. 58-68, 2019.

[25] F. Hassandoust, 'The Impact of Individual's Identities on the Infusion of Information Systems within Organisations', Auckland University of Technology, 2017.

[26] R. Alahmad, C. Pierce, M. Carter, and L. Robert, 'The impact of enterprise social media identity on job performance and job satisfaction', in Americas Conference on Information Systems 2018: Digital Disruption, AMCIS 2018, 2018.

[27] R. Alahmad and L. Robert, 'Technology Affordances and IT Identity', in Proceedings of the Twenty-third DIGIT Workshop, 2018, vol. 12.

[28] R. Alahmad and L. Robert, 'Artificial Intelligence (AI) and IT identity: Antecedents Identifying with AI Applications', in AMCIS 2021 - America's Conference on Information Systems, 2020.

[29] E. Curley and G. Polites, 'The Optimal Experience: Social Identity and IT Identity as Antecedents of Group Flow in Social Media Use', in Proceedings of the 53rd Hawaii International Conference on System Sciences (HICSS), 2020, pp. 664-673.

[30] Y. W. E. da Costa Netto and A. C. G. Maçada, 'The 
Antecedents of IT Identity Construction through Social Media Usage', in ANPAD 43rd. conference, 2019.

[31] L. Boroon, B. Abedin, and S. S. Erfani, 'Addiction to Social Network Site Use : An Information Technology Identity Perspective', in Australasian Conference on Information Systems, 2019, pp. 297303.

[32] Y. Li, S. Yang, S. Zhang, and W. Zhang, 'Mobile social media use intention in emergencies among Gen Y in China: An integrative framework of gratifications, task-technology fit, and media dependency', Telemat. Informatics, vol. 42, p. 101244, Sep. 2019.

[33] F. V. de Moura, 'Media identity and social anxiety in computer-mediated communication: predicting electronic media preference and use', ESCOLA DE ADMINISTRAÇÃO DE EMPRESAS DE SÃO PAULO, 2019.

[34] R. Sundrup, J. Windeler, and C. Froehle, 'The Social Implications of Wearable Information Technologies: Extending IT Identity Theory', in Proceedings of the 2019 on Computers and People Research Conference - SIGMIS-CPR '19, 2019, pp. 103-108.

[35] O. Ogbanufe and N. Gerhart, 'The mediating influence of smartwatch identity on deep use and innovative individual performance', Inf. Syst. J., vol. n/a, no. n/a, Apr. 2020.

[36] P. Esmaeilzadeh, 'How does IT identity affect individuals' use behaviors associated with personal health devices (PHDs)? An empirical study', Inf. Manag., p. 103313, 2020.

[37] K. Nash and R. Wakefield, 'Dare to be green: The role of environmental passion and green IT identity on green IT practices', in 25th Americas Conference on Information Systems, AMCIS 2019, 2019.

[38] Y. Shi, R. Booth, and J. Simon, 'The Iterative Effect of IT Identity on Employee Cybersecurity

Compliance Behaviors', AMCIS 2017 Proc., pp. 15, 2017.

[39] M. Schmalz, M. Carter, and J. H. Lee, 'The I in team: IT identity and project behavior', 25th Am. Conf. Inf. Syst. AMCIS 2019, 2019.

[40] Y. Li, M. Carter, and R. E. Crossler, 'A Review on Consumer Health Information Technology Research in IS', in Proceedings of the 53rd Hawaii International Conference on System Sciences, 2020.

[41] J. Sarabadani, M. Carter, and D. Compeau, '10 Years of Research on Technostress Creators and Inhibitors: Synthesis and Critique', 2018.

[42] S. A. Eidhof, 'Exploring elementary school teachers? professional information technology (IT) identity', University of Twente, 2018.

[43] Q. Weng, W. Wang, and J. Patel, 'Exploring the formation of IT identity: A technology-value fit model', in 25th Americas Conference on Information Systems, AMCIS 2019, 2019.

[44] T. L. Huang, 'Psychological mechanisms of brand love and information technology identity in virtual retail environments', J. Retail. Consum. Serv., vol. 47, no. November 2018, pp. 251-264, 2019.

[45] T.-L. Huang, 'Creating a commercially compelling smart service encounter', Serv. Bus., vol. 12, no. 2, pp. 357-377, Jun. 2018.

[46] A. Oyedele and P. M. Simpson, 'Streaming apps: What consumers value', J. Retail. Consum. Serv., vol. 41, no. April, pp. 296-304, 2018.

[47] I. Ajzen, 'The theory of planned behavior', Organ. Behav. Hum. Decis. Process., vol. 50, no. 2, pp. 179-211, 1991.

[48] S. C. Srivastava, S. Chandra, and A. Shirish, 'Technostress creators and job outcomes: theorising the moderating influence of personality traits', Inf. Syst. J., vol. 25, no. 4, pp. 355-401, 2015.

[49] V. Venkatesh and M. G. Morris, 'Why don't men ever stop to ask for directions? Gender, social influence, and their role in technology acceptance and usage behavior', MIS Q., pp. 115-139, 2000.

[50] S. You and L. Robert, 'Emotional Attachment, Performance, and Viability in Teams Collaborating with Embodied Physical Action (EPA) Robots', $J$. Assoc. Inf. Syst., vol. 19, no. 5, pp. 377-407, May 2018.

[51] L. Lapointe and S. Rivard, 'A multilevel model of resistance to information technology implementation', MIS Q., pp. 461-491, 2005.

[52] M. D. Myers, Qualitative research in business and management. Sage Publications Limited, 2019.

[53] J. Sarabadani, D. Compeau, and M. Carter, 'An Investigation of IT Users' Emotional Responses to Technostress Creators', in Proceedings of the 53rd Hawaii International Conference on System Sciences, 2020.

[54] C. B. Califf, S. Sarker, and S. Sarker, 'The Bright and Dark Sides of Technostress: A Mixed-Methods Study Involving Healthcare IT.', MIS Q., vol. 44, no. $2,2020$.

[55] A. Beaudry and A. Pinsonneault, 'Understanding user responses to information technology: A coping model of user adaptation', MIS Q., pp. 493-524, 2005.

[56] A. Beaudry and A. Pinsonneault, 'The other side of acceptance: studying the direct and indirect effects of emotions on information technology use', MIS Q., pp. 689-710, 2010.

[57] M.-K. Stein, S. Newell, E. L. Wagner, and R. D. Galliers, 'Coping with information technology: mixed emotions, vacillation, and nonconforming use patterns', Mis Q., 2015. 